\title{
Dual positive and negative control of Chlamydomonas PIl signal transduction protein expression by nitrate/nitrite and NO via the components of nitric oxide cycle
}

\author{
Zhanneta Zalutskaya, Lidiya Kochemasova and Elena Ermilova* [D
}

\begin{abstract}
Background: The PII proteins constitute a large superfamily, present in all domains of life. Until now, Pll proteins research in Chloroplastida (green algae and land plants) has mainly focused on post-translation regulation of these signal transductors. Emerging evidence suggests that PII level is tightly controlled with regard to the nitrogen source and the physiological state of cells.

Result: Here we identify that a balance of positive (nitrate and nitrite) and negative (nitric oxide) signals regulates Chlamydomonas GLB1. We found that PII expression is downregulated by ammonium through a nitric oxide (NO)dependent mechanism. We show that nitrate reductase (NR) and its partner, truncated hemoglobin 1 (THB1), participate in a signaling pathway for dual control of GLB1 expression. Moreover, NO dependent guanilate cyclase appeared to be involved in the negative control of GLB1 transcription.

Conclusion: This study has revealed the existence of the complex GLB1 control at transcription level, which is dependent on nitrogen source. Importantly, we found that GLB1 gene expression pattern is very similar to that observed for nitrate assimilation genes, suggesting interconnecting/coordinating Pll-dependent and nitrate assimilation pathways.
\end{abstract}

Keywords: Chlamydomonas reinhardtii, Nitrate, Nitrite, NO signaling, Pll signal transduction protein, Truncated hemoglobin

\section{Background}

Inorganic nitrogen $(\mathrm{N})$ acts as one of the most important mineral nutrients for all autotrophic organisms including plants. In natural ecosystems, the availability of nitrogen is often a limiting factor for plant growth. Plants have evolved highly efficient and selective systems for nitrogen acquisition to ensure an appropriate utilization of the scarce resources. In all domains of life [1-3] with representatives in most bacteria and in many archaea $[4,5]$ as well as in oxygenic eukaryotic phototrophs [6], regulation of $\mathrm{N}$ metabolism at various levels are coordinated by members of PII signal transduction proteins $[7,8]$. PII proteins act as reporters of the metabolic state of the cell by interdependent binding of ATP/

* Correspondence: e.ermilova@spbu.ru

Biological Faculty, Saint-Petersburg State University, Saint-Petersburg, Russia
ADP and 2-oxoglutarate (2-OG) [9-11]. The conserved mode of PII function is based on the control of PII - target protein interactions via the effector molecules binding [12]. Furthermore, in plants, the cellular glutamine levels are additionally sensed via PII signaling $[8,12,13]$.

A second, phylogenetically diverse regulatory mechanism is covalent modification of apical residues of the $\mathrm{T}$ loop in PII proteins that allows the integration of additional signals. In proteobacteria, actinobacteria and cyanobacteria PII proteins can be covalently modified by uridylylation, adenylylation and phosphorylation at the $\mathrm{T}$ loop residues, respectively [14-16].

However, in many other organisms, this second regulatory layer of covalent modification of the $\mathrm{T}$ loop is apparently missing, as in Archaea [7], Bacillus [17], and plant PII proteins $[6,18]$. The lack of this regulatory 
level can be partially compensated by control of PII-encoding genes at transcription level [19]. In Chloroplastida (green algae and land plants) PII-encoding GLB1 genes are nuclear-encoded and, in Rhodophyta they are coded by the plastid genome [6]. It is believed that regulation of PII in plants may be transcriptional [20-22]. However, unlike bacteria, the transcriptional control of plant PII expression remains poorly understood.

Chlamydomonas reinhardtii (Chlamydomonas in the following) is a model alga that shares with higher plants the capability of controlling by PII the activity of $\mathrm{N}$-acetyl-L-glutamate kinase (NAGK) that leads to arginine formation [8]. Although Chlamydomonas efficiently uses nitrate and nitrite, ammonium is preferred $\mathrm{N}$ source and many genes involved in nitrate/nitrite assimilation are repressed in the presence of ammonium $[23,24]$. It is also important to note that amino acids are extracellularly deaminated by Chlamydomonas and only ammonium enters the cells [25]. Given that ammonium depletion induces Chlamydomonas GLB1 upregulation [21], we hypothesized that ammonium may play a role in such negative regulation and this gene may respond to a balance of negative and positive signals.

In Chlamydomonas, ammonium and nitric oxide (NO) inhibit the expression of high-affinity nitrate/nitrite transporters and nitrate reductase (NR) [24]. During the cycle $\mathrm{NO}_{3}{ }^{-} \rightarrow \mathrm{NO}_{2}{ }^{-} \rightarrow \mathrm{NO} \rightarrow \mathrm{NO}_{3}{ }^{-}$the negative signal of $\mathrm{NO}$ can be converted back to the positive signal of nitrate. Recent publications have uncovered the function of NR in this cycle [26]. NR acts as an essential partner protein of the nitric oxide-forming nitrite reductase (NOFNiR) that catalyzes the formation of $\mathrm{NO}$ from nitrite [27]. Furthermore, NR is a protein partner of truncated hemoglobin 1 (THB1) for the conversion of NO into nitrate [28]. In spite of the key role of nitrate as a major nutrient and signal molecule, its possible regulatory effects on GLB1 transcription have not been analyzed. In order to understand the processes PII is involved in, it is important to know how GLB1 gene expression is regulated and when the amount of this protein is increased.

This apparent gap in the information about plant PII control motivated us to investigate the role of the components of cycle $\mathrm{NO}_{3}{ }^{-} \rightarrow \mathrm{NO}_{2}{ }^{-} \rightarrow \mathrm{NO} \rightarrow \mathrm{NO}_{3}{ }^{-}$in regulating GLB1 transcription in Chlamydomonas cells. In this work, we unveil that GLB1 expression responds to an extracellular $\mathrm{NO}_{3}{ }^{-} / \mathrm{NH}_{4}{ }^{+}$balance. Moreover, we show that nitrate and nitrite induce GLB1, and NO represses this gene. Collectively, these results suggest that the NR and its partners, NOFNiR and THB1, participate in a signaling pathway for dual control of GLB1 expression.

\section{Methods}

Algal strains, growth conditions and cell treatment

The following Chlamydomonas reinhardtii strains were used: wild-type cw15-325 ( $m t+, c w 15$, arg7), which was kindly provided by Dr. M. Schroda (University of Kaiserslautern, Germany) and transformants with reduced THB1 obtained from cw15-325 amiTHB1-11 $(m t+, c w 15)$, amiTHB1-14 $(m t+, c w 15)$ and $a m i$ THB123 (mt+, cw15) [29]. The 305 mutant ( $m t^{-}$nit1) affected in $\mathrm{NAD}(\mathrm{P}) \mathrm{H}-\mathrm{NR}$ activity and without diaphorase-NR activity was originally obtained from the wild type $6145 \mathrm{c}$ $\left(m t^{-}\right)$[30]. The 305 and 6145 strains were kindly provided by Dr. E. Fernández (University of Córdoba, Spain).

Cells were grown mixotrophically in tris-acetate-phosphate (TAP) medium (https://www.chlamycollection.org/methods/media-recipes/tap-and-tris-mini$\mathrm{mal} /$ ) containing $7.5 \mathrm{mM} \mathrm{NH} \mathrm{m}_{4} \mathrm{Cl}$ instead of $\mathrm{NH}_{4} \mathrm{NO}_{3}$ under continuous illumination with white light (fluence rate of $45 \mu \mathrm{mol} \mathrm{m}^{-2} \mathrm{~s}^{-1}$ ) at $22^{\circ} \mathrm{C}$ with constant orbital agitation at $90 \mathrm{rpm}$. The TAP medium was supplemented with $100 \mathrm{mg}$ $\mathrm{L}^{-1}$ of arginine when required. Cells were collected at the midexponential phase of growth by centrifugation $(4000 \mathrm{~g}$, $5 \mathrm{~min}$ ), washed twice with $10 \mathrm{mM}$ potassium phosphate, $\mathrm{pH} 7$, before being transferred to the induction media containing the different sources of nitrogen and chemicals. At each harvesting times the number of viable cells were counted microscopically with use of $0.05 \%(v / v)$ Evans blue (DIA-M, Russia) as described [31]. Non-viable (stained) and viable (unstained) cells were counted. Four-hundred cells from each sample were scored for three biological replicates.

Determination and calculations of total chlorophyll $(\mu \mathrm{g} / \mathrm{ml})$ were performed as previously described $[29,32]$.

The compounds DEA-NONOate [2-( $N$, Ndiethylamino)-diazenolate 2-oxide sodium salt] and ODQ $[1 \mathrm{H}-(1,2,4])$ oxadiazolo(4,3-a) quinoxalin-1-one] are from Sigma-Aldrich.

\section{Gene expression analysis}

The total RNA was isolated with Trizol according to the manufacturer's instructions (Invitrogen, USA). To remove genomic DNA, the RNA samples were treated with RNase-Free DNase I (Fermentas). Subsequently, RNA concentration and purity $(260 / 280 \mathrm{~nm}$ ratio) was determined using spectrophotometer (SmartSpec Plus, Bio-Rad).

Revert Aid HMinus First Strand cDNA Synthesis Kit (Thermo Scientific) was used for reverse transcription reaction. The primer pairs for RTqPCR are given in Additional file 1: Table S1. RT qPCR was performed with a CFX96 Real-Time PCR Detection System (Bio Rad) using SYBR Green I according to [33]. Gene expression ratios were calculated with the $\triangle \triangle \mathrm{Ct}$ method [34]. The RACK1 (receptor of activated protein kinase C; Cre13.g599400) gene was 
chosen as the control housekeeping gene. All reactions were performed in triplicate with at least three biological replicates. Significant differences between experiments were evaluated statistically by standard deviation and Student's t-test methods.

\section{Protein gel blot analysis}

The protein content was determined with amido black staining and protein gel blot analysis was performed as described [33, 35]. After separation by SDS-PAGE on a $12 \%$ polyacrylamide gel $(w / v)$, the proteins were transferred to nitrocellulose membranes (Carl Roth, Karlsruhe) with use of semidry blotting (Trans-blot SD BioRad). The dilutions of the primary antibodies used were as follows: 1:5,000 anti-CrPII and 1:2000 anti-HSP70B. As a secondary antibody, the horseradish peroxidase-conjugated anti-rabbit serum (Sigma) was used at a dilution of 1:10,000. The peroxidase activity was detected via an enhanced chemiluminescence assay (Roche). For quantification, films were scanned using Bio-Rad ChemiDocTMMP Imaging System, and signals were quantified using the Image LabTM software (version 5.1).

\section{Nitrate determination}

After eliminating the cells by centrifugation at $3000 \mathrm{~g}$, nitrate concentrations in the medium were determined by dual-wavelength ultraviolet spectrophotometry as $A_{220}-2 A_{275}$ using standard curve [36]. For the measurements, media with $4 \mathrm{mM}$ nitrate were diluted 50-fold. Values were obtained from at least three biological replicates; each replicate was analyzed three times. Student's $t$-tests were used for statistical comparisons. $P$-values of $<0.05$ were considered as significant.

\section{Measurement of NO}

Cells were treated with DEA-NONOate or nitrite, then they were incubated with in the presence of $1 \mu \mathrm{M}$ (4-amino-5-methylamino-2'7'-difluorofluorescein diacetate) dye (DAF-FM DA, Sigma-Aldrich), at concentration of $45 \mu \mathrm{g} /$ $\mathrm{ml}$ chlorophyll. After $15 \mathrm{~min}$ the cells were washed, resuspended in indicated medium and used for the fluorometric detection of NO. The supernatant was collected in a test tube and then used to detect NO in the medium. The measurement of NO was carried out with a microplate reader CLARIOstar (BMG) as described [29]. The excitation and emission wavelengths for the $\mathrm{NO}$ indicator were $483 \pm 14$ and $530 \pm 30 \mathrm{~nm}$, respectively. Fluorescence intensity was calculated as arbitrary units per chlorophyll or protein as described previously [29].

\section{NO detection by confocal microscopy}

Cells were treated as described above. Images were acquired with a Leica TCS-SP5 confocal microscope
(Leica-Microsystems, Germany) as described [29]. All experiments were performed in triplicate.

\section{Results \\ GLB1 is induced by nitrate}

Ammonium and nitrate are the main nitrogen sources for Chlamydomonas [37, 38]. There is evidence that GLB1 transcript levels are rather low in cells grown in the presence of ammonium [21]. We wanted to investigate whether or not the expression of GLB1 is influenced by nitrate. In cw15-325, upregulation of GLB1 was detected in nitrate alone (Fig. 1a). Nitrate applied at concentration of $4 \mathrm{mM}$ has been reported previously to induce NIT1 gene encoding nitrate reductase [24]. In 4 $\mathrm{mM} \mathrm{NO}{ }_{3}^{-}$-exposed cells, the GLB1 transcript level was increased after $30 \mathrm{~min}$ and reached a maximum within $1-3 \mathrm{~h}$ of incubation. During further exposure to nitrate, the gene expression decreased again approximately 2.4 times higher than the control level. When Chlamydomonas cells were exposed to $100 \mu \mathrm{M}$ nitrate, we observed the same expression levels as in $4 \mathrm{mM}$ nitrate medium. Decreasing the nitrate concentration to $10 \mu \mathrm{M}$ resulted in an even higher increase in the GLB1mRNA abundance (2.3 fold after $30 \mathrm{~min}$ and 4.5 -fold after $1 \mathrm{~h}$ ) (Fig. 1a). Importantly, during exposure of cw15-325 cells ( $\arg 7-8)$ to nitrate, arginine was added to the medium. Thus, the observed increase in GLB1 transcripts was not caused by nitrogen starvation. Moreover, nitrate remaining in the media during experiment was also assayed (Fig. 1b). The data suggest that that a saturating effect observed between $4 \mathrm{mM}$ and $90 \mu \mathrm{M}$ of nitrate.

Interestingly, GLB1 demonstrated a rather similar expression pattern to NIT1 (Fig. 1a, insertion). However, in contrast to GLB1, the higher levels of NIT1 up-regulation were reached when cells were exposed to $4 \mathrm{mM}$ nitrate.

Next, we asked the question whether the nitrate-induced upregulation of GLB1 expression is accompanied by an increase in the PII protein. Compared to cells grown in ammonium, levels of PII were indeed higher in cells incubated in nitrate (Fig. 1c). The data suggest that the PII is induced by nitrate.

\section{GLB1 transcription responds to the $\mathrm{NH}_{4}{ }^{+} / \mathrm{NO}_{3}{ }^{-}$balance}

In Chlamydomonas, the $\mathrm{NH}_{4}{ }^{+} / \mathrm{NO}_{3}{ }^{-}$balance was shown to be sensed by cells modulating expression of the nitrogen pathway genes [39]. To test whether GLB1 transcription responds to a balance of $\mathrm{NH}_{4}{ }^{+}$and $\mathrm{NO}_{3}{ }^{-}$, we monitored the accumulation of GLB1 transcripts in Chlamydomonas cells incubated in media containing different concentrations of $\mathrm{NH}_{4}{ }^{+}(1 \mathrm{mM}$ or $7.5 \mathrm{mM})$ with 4 $\mathrm{mM} \mathrm{NO}{ }_{3}^{-}$. In cells supplemented with $4 \mathrm{mM} \mathrm{NO}_{3}{ }^{-}+7.5$ $\mathrm{mM} \mathrm{NH}_{4}{ }^{+}$GLB1 expression was fully blocked (Fig. 2a). However, GLB1 mRNA abundance was higher in $4 \mathrm{mM}$ $\mathrm{NO}_{3}{ }^{-}+1 \mathrm{mM} \mathrm{NH}_{4}{ }^{+}$, although significantly lower than in 

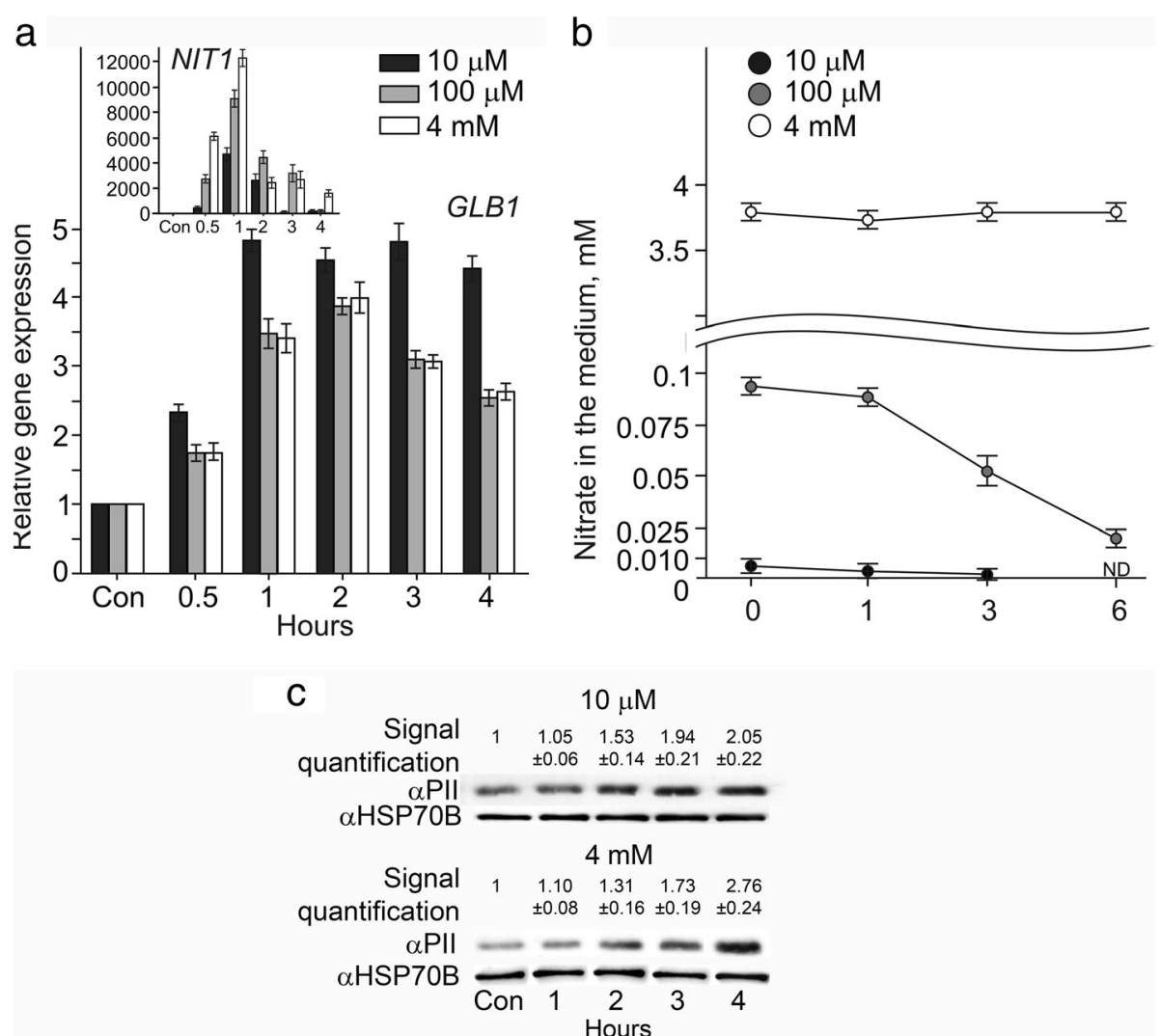

Fig. 1 PII expression is increased by nitrate. a Time course of the GLB1 transcripts accumulation during incubation of illuminated cells in nitratecontaining medium. Chlamydomonas cells of cw15-325 strain were grown in ammonium-containing medium (Con, control) and transferred to media containing $4 \mathrm{mM}, 100 \mu \mathrm{M}$, or $10 \mu \mathrm{M} \mathrm{NO}_{3}{ }^{-}$in the light for $0.5 \mathrm{~h}, 1 \mathrm{~h}, 2 \mathrm{~h}$ or $4 \mathrm{~h}$. Values are means \pm SE of three biological replicates and three technical replicates and are given as expression level relative to a house-keeping gene RACK1 that has a value of 1.The increase in NIT1 transcript abundance was used as a positive control (insertion). b Changes in nitrate levels in the media. Chlamydomonas cells of cw15-325 strain were grown in ammoniumcontaining medium and transferred to media containing $4 \mathrm{mM}, 100 \mu \mathrm{M}$, or $10 \mathrm{\mu M} \mathrm{NO}_{3}{ }^{-}$in the light. At the indicated times, the amounts of nitrate present in the media were quantified. ND, not determined. Values are means \pm SE of three biological replicates. cTime course of the PII protein accumulation during incubation of illuminated cells in nitrate-containing medium. Pll levels were analyzed by western blotting in the same conditions as in (a). Each line corresponds to $20 \mathrm{\mu g}$ of soluble proteins extracted from samples taken from cultures at the time points indicated. Quantitation of protein blots is given as proportion of signal in test variant to control variant. HSP70B signal served as a loading control

$4 \mathrm{mM} \mathrm{NO}_{3}{ }^{-}$medium. Therefore, like NIT1 (Fig. 2, insertion; [39]) GLB1 expression responds quantitatively to extracellular $\mathrm{NH}_{4}{ }^{+}$. Moreover, addition of $1 \mathrm{mM} \mathrm{NH}_{4}^{+}$to media containing different concentrations of $\mathrm{NO}_{3}^{-}(4$ $\mathrm{mM}, 100 \mu \mathrm{M}$ and $10 \mu \mathrm{M})$ caused the more severe reduction in GLB1 transcription at the lowest nitrate concentration (Fig. 2b). These data additionally support the idea that and $\mathrm{NH}_{4}{ }^{+} / \mathrm{NO}_{3}{ }^{-}$balance may play an important role in the regulation of the gene of interest.

\section{GLB1 is repressed by NO}

Stimulation of NO generation has been reported to be dependent on the ammonium concentration in the medium and as a consequence to control the expression of the nitrogen pathway genes in Chlamydomonas cells [24]. The above results (Fig. 2) suggest that NO may be involved in the control of GLB1 expression. To test this, the nitrate-induced cells were treated with DEA-NONOate as NO donor [40]. The concentrations of DEA-NONOate used $(10 \mu \mathrm{M}, 50 \mu \mathrm{M}$, and $100 \mu \mathrm{M})$ caused a significant inhibition of GLB1 expression after $30 \mathrm{~min}$ (Fig. 3a). Interestingly, the expression of this gene was largely recovered after $1 \mathrm{~h}$ and $3 \mathrm{~h}$ in the presence of $10 \mu \mathrm{M}$ or $50 \mu \mathrm{M}$ and $100 \mu \mathrm{M}$ DEA-NONOate, respectively, hinting that NO may be converted in $\mathrm{NO}_{3}{ }^{-}$for this period. DEA-NONOate also exhibited a negative effect on the transcription of NIT1 used as a control gene (Fig. 3a, insertion). These results are consistent with a balance of NO levels detected in cells and in culture broth (Fig. 3b). The combined real-time PCR and $\mathrm{NO}$ detection analysis suggested that mRNA levels of GLB1 were repressed by NO. We also propose that there is subtle regulation of the NO levels which control GLB1 expression, probably through fine tuning of the components mediating cycle $\mathrm{NO}_{3}{ }^{-} \rightarrow \mathrm{NO}_{2}{ }^{-} \rightarrow \mathrm{NO} \rightarrow \mathrm{NO}_{3}{ }^{-}$. 

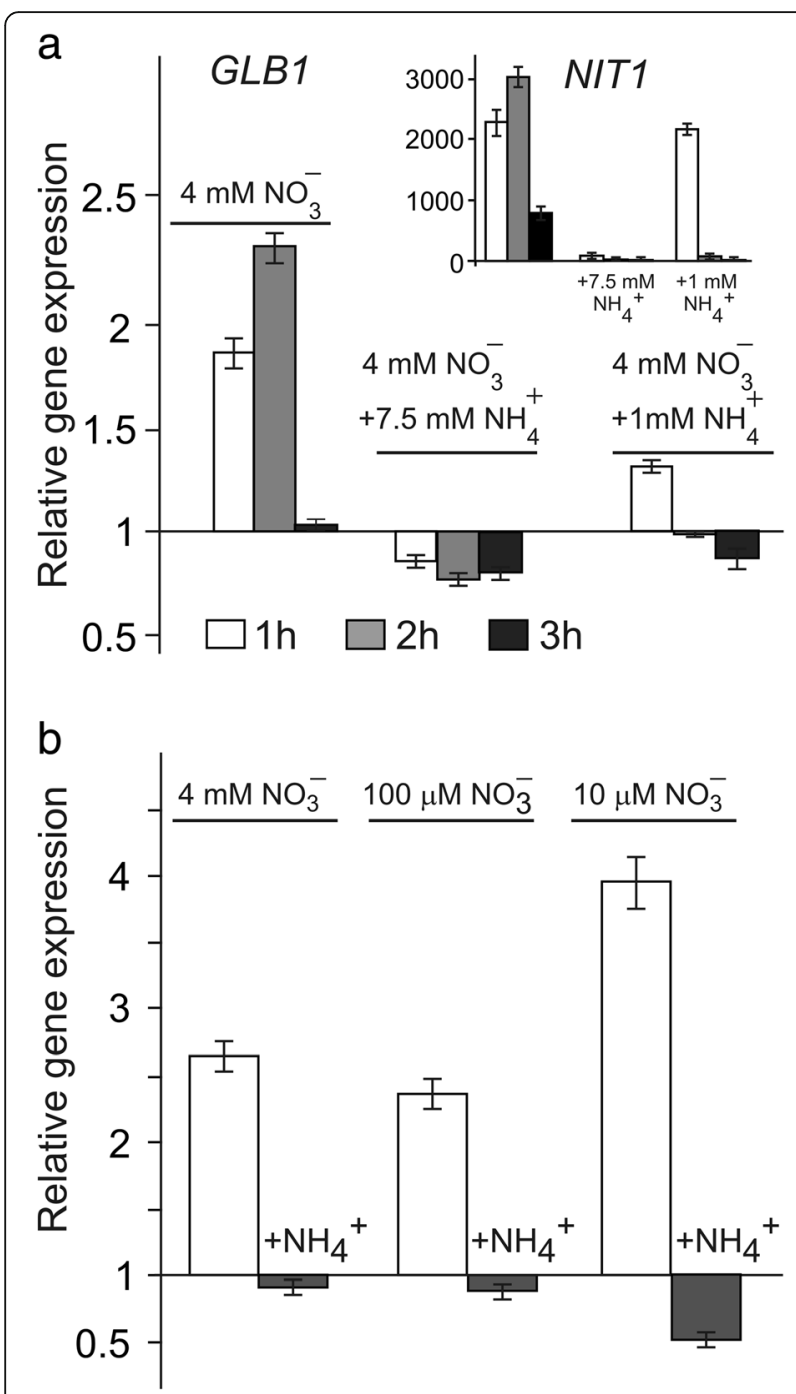

Fig. 2 GLB1 transcription depends on the balance of ammonium and nitrate in the medium. a GLB1 transcript levels were determined in Chlamydomonas cells of cw15-325 strain grown in ammoniumcontaining medium and transferred to media containing $4 \mathrm{mM} \mathrm{NO}_{3}{ }^{-}, 4$ $\mathrm{mM} \mathrm{NO}_{3}{ }^{-}+7.5 \mathrm{mM} \mathrm{NH}_{4}{ }^{+}$or $4 \mathrm{mM} \mathrm{NO}_{3}{ }^{-}+1 \mathrm{mM} \mathrm{NH}_{4}{ }^{+}$. Values are means \pm SE of three biological replicates and three technical replicates and are given as expression level relative to a house-keeping gene RACK1 that has a value of 1. Expression level at $0.5 \mathrm{~h}$ is considered as a control. The increase in NIT1 transcript abundance was used as a positive control (insertion). b GLB1 transcript levels were determined in Chlamydomonas cells of cw15-325 strain grown in ammoniumcontaining medium and transferred to media containing the indicated concentrations of $\mathrm{NO}_{3}{ }^{-}$and $1 \mathrm{mM} \mathrm{NH}_{4}{ }^{+}$for $2 \mathrm{~h}$. Values are means $\pm \mathrm{SE}$ of three biological replicates and three technical replicates and are given as expression level relative to a house-keeping gene RACK1 that has a value of 1

Nitrite induces GLB1 gene and NR promotes NOdependent GLB1 repression

In Chlamydomonas cells, NO appears as a consequence of nitrite accumulation [28]. To further explore the relationship between GLB1 expression levels and NO generation, two strains were assayed: the wild strain $6145 \mathrm{c}$ and its derivative mutant 305 , which, affected in NAD(P) H-NR activity and without diaphorase-NR activity. Both strains were incubated in $10 \mathrm{mM}$ nitrite. Unexpectedly, nitrite increased GLB1 transcript levels in cells (Fig. 4a). In addition, the nit1 mutant showed higher levels of GLB1 expression than WT (6145c), consistent with inability of the strain 305 to supply $\mathrm{NAD}(\mathrm{P}) \mathrm{H}$ electrons to nitrite [27].

Next, we asked the question whether the increased GLB1 mRNA levels correlate with a change in PII protein content in nitrite-induced cells. Although the kinetics of changes in GLB1 mRNA levels were not similar to the kinetics of changes in PII protein levels in both strains, the difference in PII protein abundance between parental strain $6145 \mathrm{c}$ and mutant 305 (Fig. 4b) was evident. The data suggest that GLB1 upregulation is dependent of nitrite. This result is in agreement with the fact that the NR mutant without diaphorase-NR activity did not show significant NO signal (Fig. 4c and d). In contrast to the mutant, very strong NO fluorescence appeared in the $6145 \mathrm{c}$ strain, supporting a correlation between NO generation and GLB1 mRNA abundance. Thus, these experiments allow nitrite to be added as a player in the control of GLB1 expression together with nitrate and NO. Taken together, the results strengthen the idea that control of GLB1 expression is regulated by a complex mechanism in which NO produced via NR/ NOFNiR plays a crucial role.

THB1 controls GLB1 expression via the detoxification of NO Previously, it was shown that NR uses the truncated hemoglobin THB1 in the conversion of NO to nitrate [28]. We therefore asked whether THB1 exerts any effect on the expression of GLB1. To test this, the cells of cw15-325 (WT) and THB1 knock-down strains were incubated in $4 \mathrm{mM}$ nitrate with or without DEA-NONOate. Nitrate-induced expression of GLB1 was shown to be antagonized by NO (Figs. 3 and 4). As shown in Fig. 5, the downregulation of THB1 impaired the transcription of GLB1 in the presence of NO generator: compared with cw15-325, transcript accumulation for gene of interest in all THB1-amiRNA strains was reduced on average from 1.5-fold to 2.3-fold. These results are in agreement with the higher levels of NO measured in THB1 knock-down strains compared to parental strain (cw15-325). Collectively, these results suggest that reduction in THB1 expression allows NO concentration to increase, triggering down-regulation of GLB1 transcription.

\section{NO-dependent GLB1 repression is released by guanylate cyclase (GC) inhibitor}

Our analyses show that GLB1 is transcriptionally regulated by the same mechanisms than NIT1 gene that is 

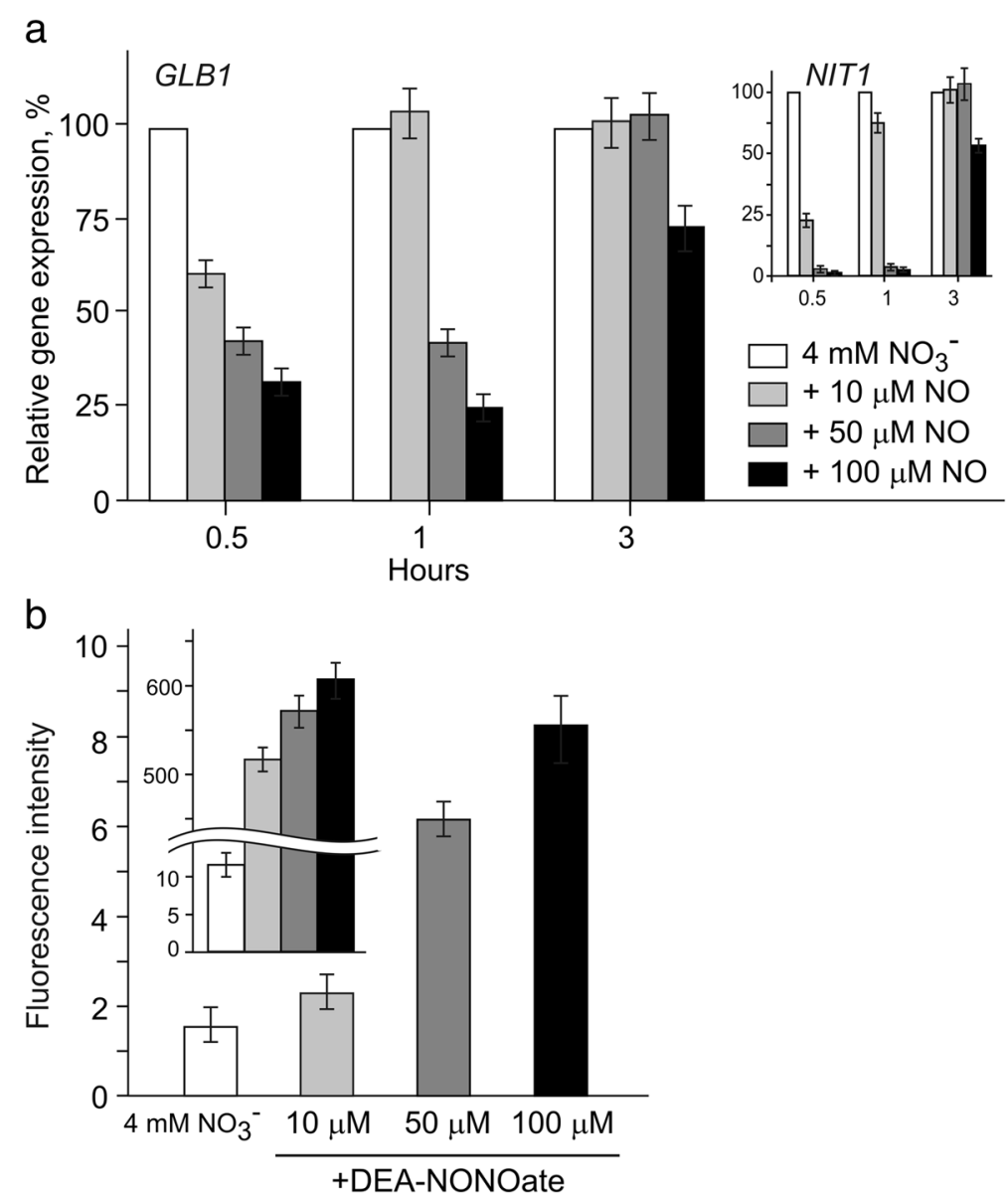

Fig. 3 Effects of DEA-NONOate on the nitrate-induced expression of GLB1 gene and the levels of intracellular nitric oxide. a The effect of DEA-NONOate $(10 \mu \mathrm{M}, 50 \mu \mathrm{M}$ or $100 \mu \mathrm{M})$ on the GLB1 transcripts accumulation was determined in $4 \mathrm{mM}$ nitrate-induced C. reinhardtii cells of cw15-325 strain for 0.5 and $1 \mathrm{~h}$. Nitrate-induced cells represent controls (set to 100\%) without the added DEA-NONOate. Values are means \pm SE of three biological replicates and three technical replicates and are given as expression level relative to a house-keeping gene RACK1 that has a value of 1. The increase in NIT1 transcript abundance was used as a positive control (insertion). b Fluorescence intensity due to intracellular NO was determined using $1 \mu$ M DAF-FM $\mathrm{DA}$ and was expressed as arbitrary units per $\mu \mathrm{g}$ protein. Cell autofluorescence was subtracted from the total fluorescence obtained. Insertion shows NO levels in the media (see Materials and Methods). Data are the means \pm SE from three independent experiments

repressed by NO (Figs. 2, 3 and 4). Repression of NIT1 by $\mathrm{NO}$ is mediated by NO-dependent GC activity [24]. It would thus be interesting to test the GC inhibitor in order to better decipher how the GLB1 transcription is inhibited by NO. We found that ODQ, a selective inhibitor of NO activated GC [41], caused derepression of the GLB1 in ammonium containing medium when applied at concentrations $2.5 \mu \mathrm{M}, 5 \mu \mathrm{M}$ or $7.5 \mu \mathrm{M}$, whereas $1 \mu \mathrm{M}$ of this inhibitor had no effect (Fig. 6). This result allows us to propose that, by sensing NO, GC activity could be involved in GLB1 repression.

\section{Discussion}

Plant chloroplasts contain cyanobacterial-like PII homologues [6]. However, unlike PII proteins from cyanobacteria, plant PII proteins seem not to be covalently modified [20, 21]. Furthermore, in cyanobacteria, PII signaling is involved in the regulation of nitrate assimilation and gene expression through co-activator of the global nitrogen control factor NtcA [5]. Importantly, no homologues of PipX and NtcA are conserved in plants [12]. In representative plants, PII proteins are regulated at the transcriptional level [20-22]. In this study, we demonstrate that expression of Chlamydomonas PII is under the complex control of positive signals (i.e., nitrate and nitrite) and negative signals (NO), and GLB1 gene expression pattern is very similar to that observed for nitrate assimilation genes.

Ammonium is the preferred nitrogen source for Chlamydomonas. In ammonium-containing medium Chlamydomonas PII is expressed at low levels [21]. Interestingly, the second major nitrogen source, nitrate, induces GLB1 transcription (Fig. 1). The cells might use this transcription regulation to limit PII levels under 

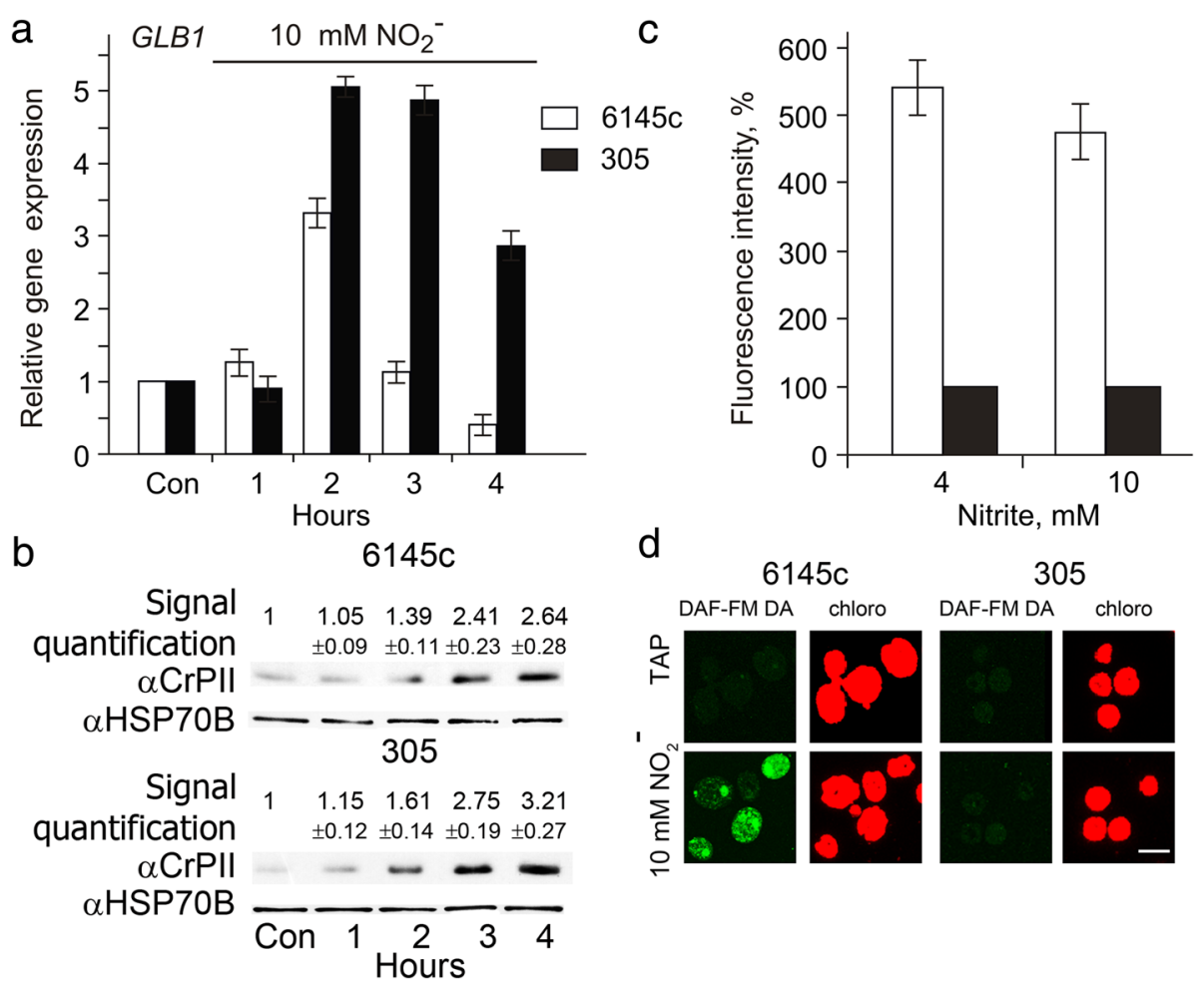

Fig. 4 Nitrate reductase promotes NO-dependent GLB1 repression. a Time course of the GLB1 transcripts accumulation during incubation of illuminated cells in nitrite-containing medium. Chlamydomonas cells of the wild strain $6145 \mathrm{C}$ and its derivative mutant 305 , affected in NAD(P) $\mathrm{H}-\mathrm{NR}$ activity and without diaphorase-NR activity, were grown in ammonium-containing medium and transferred to medium containing $10 \mathrm{mM} \mathrm{NO}_{2}{ }^{-}$in the light for 1,2 , 3 or $4 \mathrm{~h}$. Values are means \pm SE of three biological replicates and three technical replicates and are given as expression level relative to a house-keeping gene RACK1 that has a value of 1. b Time course of the Pll protein accumulation during incubation of illuminated cells of the strains $6145 \mathrm{c}$ and 305 , in nitrite-containing medium. PIl levels were analyzed by Western blotting in the same conditions as in (a). Each line corresponds to $10 \mu \mathrm{g}$ of soluble proteins extracted from samples taken from cultures at the time points indicated. Quantitation of protein blots is given as proportion of signal in test variant to control variant. HSP70B signal served as a loading control. c NO production in nitrite-induced cells. Chlamydomonas cells of the strains $6145 \mathrm{c}$ and 305 were grown in TAP medium and transferred to nitrite-containing medium in the light for 15 min. Fluorescence intensity due to intracellular NO was determined using DAF-FM DA and was expressed as arbitrary units per $\mu \mathrm{g}$ chlorophyll. Cell autofluorescence was subtracted from the total fluorescence obtained. Fluorescence in the strain 305 is considered as control (set to 100\%). Data are the means \pm SE from three independent experiments. Production of NO was measured by the microplate reader CLARIOstar (BMG). d NO visualization by confocal microscopy. Images of cells grown in TAP (TAP) or incubated in nitrite-containing medium (10 $\mathrm{mM} \mathrm{NO}_{2}^{-}$) for $15 \mathrm{~min}$. The left-hand panels show DAF-FM fluorescence (green color) while the right-hand panels show Chl autofluorescence (red color). Scale bar equals $10 \mu \mathrm{m}$

optimal nutritional conditions. It would thus be interesting to test whether GLB1 is strictly sensitive to ammonium or responds to a balance of ammonium and nitrate. We found that changes in the nitrate concentration modulate the response of GLB1 gene to ammonium (Fig. 2). Together these data stress the point that, a balance of positive and negative signals regulates GLB1.

A part of the response to ammonium/nitrate balance is a change in the intracellular concentration of $\mathrm{NO}$ [39]. We have shown herein that NO represses expression of GLB1 (Fig. 3). Interestingly, GLB1 exhibits a similar transcription pattern to NIT1 (Fig. 3a, insertion) and other genes from the nitrate assimilation cluster [24, 38, 42, 43], suggesting that the expression of PII is tightly controlled with regard to the nitrogen source and the physiological state of cells. Physiological studies of Arabidopsis suggested a role of PII in nitrite uptake [44]. In addition, GLB1 expression is up-regulated in the presence of nitrite (Fig. 4a). Together, these observations allow us to speculate that PII protein may also play some uncharacterized roles in control of nitrogen assimilation in Chlamydomonas cells.

In the cytoplasm, nitrite is converted into NO by NR that is partnered with NOFNiR [27]. Thus, NR modulates both the levels of $\mathrm{NO}$ and the amounts of nitrite available for metabolism. Importantly, the diaphorase-NR activity is required for supplying $\mathrm{NAD}(\mathrm{P}) \mathrm{H}$ electrons to nitrite [27]. We propose that GLB1 transcription is dependent on the dual system of NR and NOFNiR through fine tuning of NO levels. The fact that the diaphorase-NR activity is required to repress PII levels in the presence of nitrite (Fig. 4a; b) supports this idea. In agreement with these data, spectrofluorometric assays (Fig. 4c) and confocal microscopy (Fig. 4d) with DAF-FM DA allowed us to detect higher fluorescence levels in parental strain $6145 \mathrm{c}$ than nit1 mutant. More 

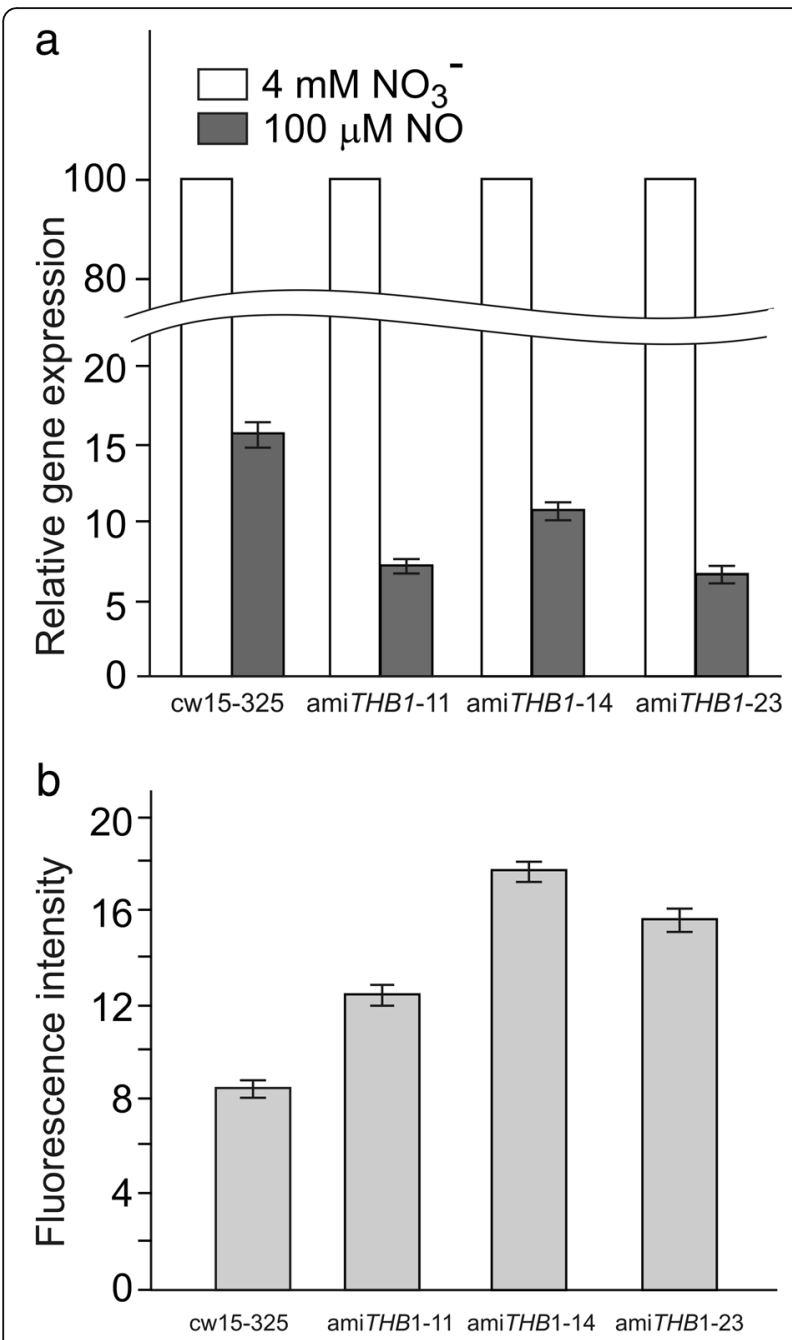

Fig. 5 Effects of reduced THB1 levels on GLB1 expression and NO generation. a Time course of the GLB1 transcripts accumulation during incubation of cw15-325 and amiRNA-THB1 cells in $4 \mathrm{mM}$ nitritecontaining medium with or without DEA-NONOate $(100 \mu \mathrm{M})$. Values are means \pm SE of three biological replicates and three technical replicates and are given as expression level relative to a house-keeping gene RACK1 that has a value of 1. $\mathbf{b}$ Fluorescence increase was measured in cW15-325 and amiRNA-THB1 cells following the incubation in $4 \mathrm{mM}$ nitrate with or without of DEA-NONOate $(100 \mu \mathrm{M})$ for $15 \mathrm{~min}$.

Fluorescence intensity due to intracellular NO was determined using DAF-FM DA and was expressed as arbitrary units per $\mu \mathrm{g}$ protein. Cell autofluorescence was subtracted from the total fluorescence obtained. Data are the means \pm SE from three technical replicates of a representative experiment. Production of $\mathrm{NO}$ was measured by the microplate reader CLARIOstar (BMG)

generally we could propose that nitrite-dependent $\mathrm{NO}$ production plays role in the control of PII expression dynamics, ensuring possible interconnecting/coordinating PII-dependent and nitrate assimilation pathways.

As NO is toxic, plants have protective mechanisms to defend themselves. Like higher plants, Chlamydomonas cells use hemoglobins to convert $\mathrm{NO}$ into nitrate $[28,45,46]$. It has been previously shown that a

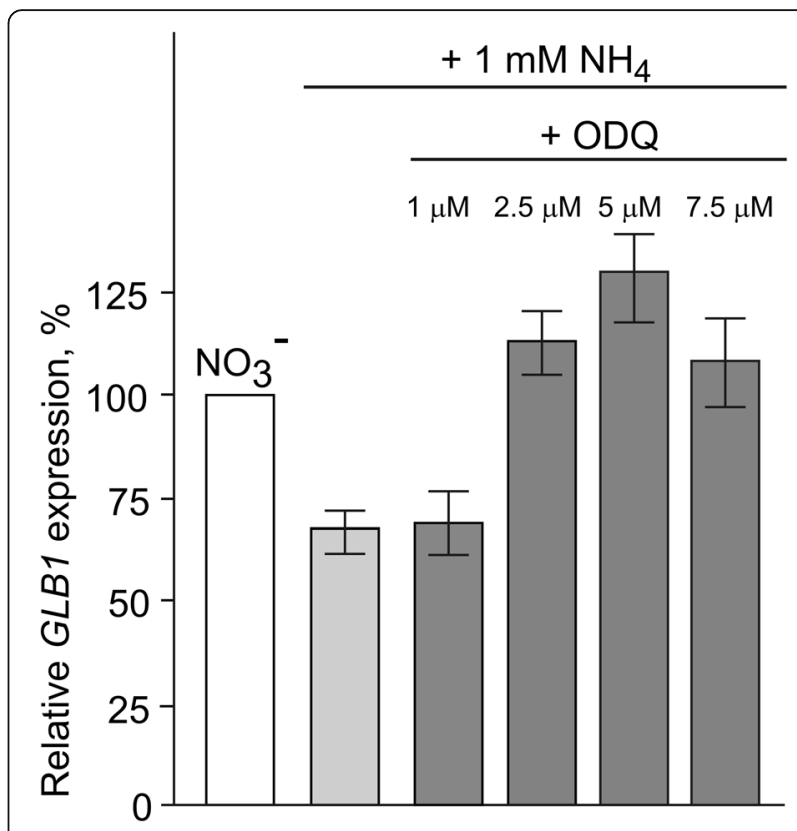

Fig. 6 Effects of guanylate cyclase inhibitor on GLB1 repression in medium containing nitrate and ammonium. GLB1 transcript levels were determined in Chlamydomonas cells of cw15-325 strain grown in ammonium-containing medium and transferred to media containing $4 \mathrm{mM} \mathrm{NO}_{3}{ }^{-}+7.5 \mathrm{mM} \mathrm{NH}_{4}{ }^{+}$with or without $1 \mu \mathrm{M}, 2.5 \mu \mathrm{M}, 5 \mu \mathrm{M}$ or $7.7 \mu \mathrm{M} 1 \mathrm{H}-[1,2,4]$ oxadiazolo-[4,3-a]quinoxalin-1-one (ODQ). Values are means \pm SE of three biological replicates and three technical replicates and are given as expression level relative to a house-keeping gene RACK1 that has a value of 1

truncated hemoglobin 1, THB1, has NO-dioxygenase activity [28]. In amiTHB1 strains, the nitrite-responsive accumulation of GLB1 transcripts is impaired (Fig. 5a). As expected, DEA-NONOate in nitrite-containing medium resulted to higher fluorescence levels in THB1-knockdown transformants than in parental strain (Fig. 5b). Taken together, these results strengthen the notion that $\mathrm{NO}$ acts as a signaling molecule for the transcriptional regulation of GLB1 gene, and THB1 is involved in this NO-dependent pathway.

The mechanism implicated in the repression of GLB1 by NO is not clear, although in Chlamydomonas, six proteins CYG11, CYG12, CYG15, CYG38, CYG56 and CYG57 share the same domains structure with mammalian NO sensors, the soluble guanylate cyclases [30, 47-49]. In animals, the GCs activity is usually stimulated by the binding of NO to their heme group [50]. Moreover, CYG56 participates in ammonium-mediated NIA1, NRT2.1, AMT1.1 and AMT1.2 repression through a pathway that involves NO and cGMP [24, 49]. Importantly, inhibition of the NO-dependent GC by ODQ releases cells from ammonium repression of not only genes from the nitrate assimilation cluster but also of GLB1 gene (Fig. 6). This correlation emphasizes that regulation of nitrate assimilation genes and GLB1 are closely related and 
support the hypothesis that a soluble guanilate cyclase may also control GLB1 expression in NO-GC-dependent manner. Interestingly, only CYG56 is up-regulated in ammonium compared with nitrate-containing medium [24], hinting that ammonium-mediated repression of GLB1 might be regulated through CYG56-dependent signaling. However, which guanylate cyclase is a pivotal factor for the regulation of GLB1 in ammonium-containing medium has to be analyzed further. The experiments described here establish ammonium as a component of the signaling pathway for the negative control of the GLB1 transcription. However, they do not address how ammonium acts to repress GLB1 gene. Moreover, we cannot rule out that NO-dependent GLB1 repression by nitrite and ammonium may go through the various routes. We propose a model (Fig. 7) in which PII expression is under complex control of positive and negative signals depending on nitrogen source.

\section{Conclusions}

Our main conclusion is that PII level is tightly controlled with regard to the nitrogen source and the physiological state of cells. We provide evidence on that $\mathrm{NO}$ via the components of nitric oxide cycle is involved in the negative control of GLB1. On the other hand, nitrate and nitrite induce this gene transcription. Therefore, important regulatory layer in the PII-dependent signal transduction system in Chlamydomonas could be that the

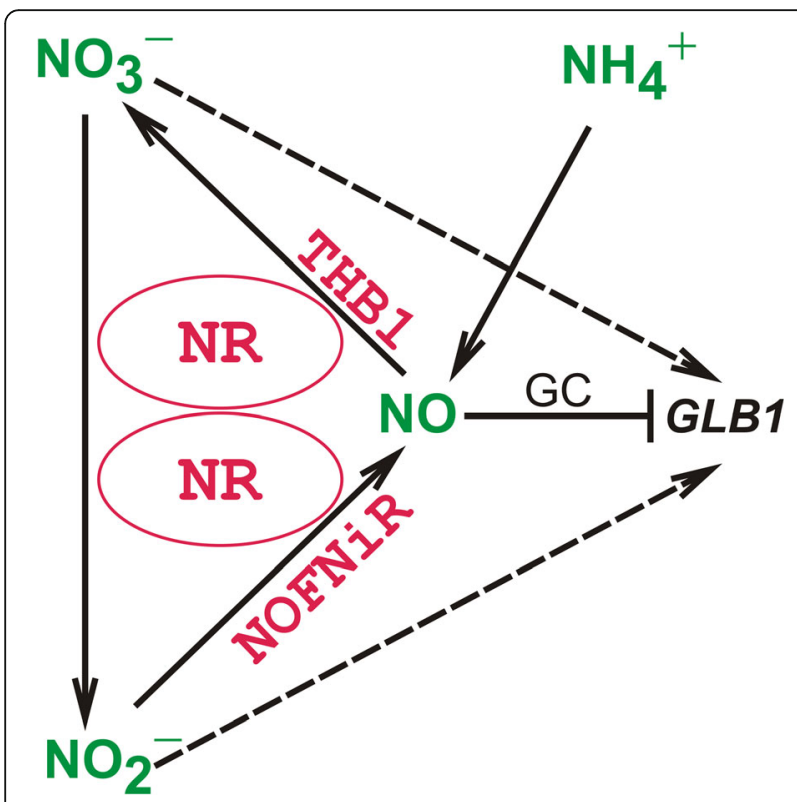

Fig. 7 Model for a nitrogen-dependent control of GLB1 expression. Nitrate and nitrite act as positive regulators of GLB1 transcription (dotted arrows). Conversely, NO that is mediated via the components of nitric oxide cycle or via a rise in intracellular ammonium, represses GLB1 transcription (thick T-like line). GC may also control GLB1 expression in NO-GC-dependent manner concentration of the PII protein must be balanced in order for the signaling mechanism to function properly - the system is fine-tuned.

\section{Additional files}

Additional file 1: Table S1. Primers sequence that were used for real time PCR analysis. (XLSX $10 \mathrm{~kb}$ )

\section{Abbreviations}

DAF-FM DA: 4-amino-5-methylamino-2'7'-difluorofluorescein diacetate; DEANONOate: 2-(N,N-diethylamino)-diazenolate 2-oxide sodium salt; GC: Guanylate cyclase; NO: Nitric oxide; NOFNiR: Nitric oxide-forming nitrite reductase; NR: Nitrate reductase; ODQ: $1 \mathrm{H}-(1,2,4)$ oxadiazolo(4,3-a) quinoxalin1-one; TAP: Tris-acetate-phosphate medium; THB1: Truncated hemoglobin 1

\section{Acknowledgements}

We thank Dr. Anton Radaev and the Core Facility "CHROMAS" of SaintPetersburg State University for assistance with confocal microscopy. We also thank Dr. Michael Schroda (TU Kaiserslautern, Germany) for kind providing of HSP70B antibody and the strain cw15-325. The supply of strains $6145 \mathrm{C}$ and 305 by Dr. Emilio Fernández (University of Córdoba, Spain) is gratefully acknowledged.

\section{Funding}

This work was supported by Saint-Petersburg State University (research Grant No. 1.65.38.2017) to EE.

\section{Availability of data and materials \\ The datasets used and/or analysed during the current study are available from the corresponding author on reasonable request.}

\section{Authors' contributions}

ZZ and LK performed all of the biological analyses. ZZ, LK and EE analyzed the data. EE designed the study and wrote the manuscript. All authors approved the final version of the manuscript.

Ethics approval and consent to participate Not applicable.

Consent for publication

Not applicable.

\section{Competing interests}

The authors declare that they have no competing interests.

\section{Publisher's Note}

Springer Nature remains neutral with regard to jurisdictional claims in published maps and institutional affiliations.

Received: 31 May 2018 Accepted: 20 November 2018 Published online: 27 November 2018

\section{References}

1. Sant'Anna FH, Trentini DB, de Souto Weber S, Ceccagno R, da Silva SC, Schrank IS. The PII superfamily revised: a novel group and evolutionary insights. J Mol Evol. 2009;68:322-36.

2. Chellamuthu VR, Alva V, Forchhammer K. From cyanobacteria to plants: conservation of PII functions during plastid evolution. Planta. 2013;237:451-62.

3. Huergo LF, Chandra G, Merrick M. PII signal transduction proteins: nitrogen regulation and beyond. FEMS Microbiol Rev. 2013;37:251-83.

4. Arcondéguy $T$, Jack R, Merrick M. Pll signal transduction proteins, pivotal players in microbial nitrogen control. MMBR. 2001;65:80-105.

5. Forchhammer K. P(II) signal transducers: novel functional and structural insights. Trends Microbiol. 2008;16:65-82.

6. Uhrig RG, Ng KK, Moorhead GB. PII in higher plants: a modern role for an ancient protein. Trends Plant Sci. 2009;14:505-11. 
7. Leigh JA, Dodsworth JA. Nitrogen regulation in bacteria and archaea. Annu Rev Microbiol. 2007:61:349-77.

8. Chellamuthu VR, Ermilova E, Lapina T, Luddecke J, Minaeva E, Herrmann C, Hartmann MD, Forchhammer K. A widespread glutamine sensing mechanism in the plant kingdom. Cell. 2014;159:1188-99.

9. Jiang P, Ninfa AJ. Sensation and signaling of a-ketoglutarate and adenylylate energy charge by the Escherichia coli PII signal transduction protein require cooperation of the three ligand-binding sites within the PII trimer. Biochemistry. 2009;48:11522-31.

10. Fokina O, Chellamuthu VR, Forchhammer K, Zeth K. Mechanism of 2oxoglutarate signaling by the Synechococcus elongatus PII signal transduction protein. Proc Natl Acad Sci U S A. 2010;107:19760-5.

11. Zeth K, Fokina O, Forchhammer K. Structural basis and target specific modulation of ADP sensing by the Synechococcus elongatus PII signaling protein. J Biol Chem. 2014;289:8960-72.

12. Lapina T, Selim KA, Forchhammer K, Ermilova E. The Pll signaling protein from red algae represents an evolutionary link between cyanobacterial and Chloroplastida PII proteins. Sci Rep. 2018;8:790.

13. Minaeva E, Forchhammer K, Ermilova E. Glutamine assimilation and feedback regulation of L-acetyl-N-glutamate kinase activity in Chlorella variabilis NC64A results in changes in arginine pools. Protist. 2015;166:493-505.

14. Forchhammer $K$, Tandeau de Marsac N. The PIl protein in the cyanobacterium Synechococcus sp. strain PCC 7942 is modified by serine phosphorylation and signals the cellular N-status. J Bacteriol. 1994;176:84-91.

15. Hesketh A, Fink D, Gust B, Rexer HU, Scheel B, Chater K, Wohlleben W, Engels A. The GlnD and GlnK homologues of Streptomyces coelicolor A3(2) are functionally dissimilar to their nitrogen regulatory system counterparts from enteric bacteria. Mol Microbiol. 2002;46:319-30.

16. Ninfa AJ, Jiang P. PII signal transduction proteins: sensors of alpha-ketoglutarate that regulate nitrogen metabolism. Curr Opin Microbiol. 2005;8:168-73.

17. Heinrich A, Woyda K, Brauburger K, Meiss G, Detsch C, Stulke J, Forchhammer K. Interaction of the membrane-bound GlnK-AmtB complex with the master regulator of nitrogen metabolism TnrA in Bacillus subtilis. J Biol Chem. 2006;281:34909-17.

18. Smith CS, Morrice NA, Moorhead GB. Lack of evidence for phosphorylation of Biochim. Biophys Acta. 1699;2004:145-54.

19. Amon J, Titgemeyer F, Burkovski A. Common patterns - unique features: nitrogen metabolism and regulation in gram-positive bacteria. FEMS Microbiol Rev. 2010;34:588-605.

20. Hsieh MH, Lam HM, van de Loo FJ, Coruzzi G. A Pll-like protein in Arabidopsis: putative role in nitrogen sensing. Proc Natl Acad Sci U S A. 1998;95:13965-70

21. Ermilova E, Lapina T, Zalutskaya Z, Minaeva E, Fokina O, Forchhammer K. PII signal transduction protein in Chlamydomonas reinhardtii: localization and expression pattern. Protist. 2013;64:49-59.

22. Ma R, Li Y, Lu Y. Sequencing and characterization of novel Pll signaling protein gene in microalga Haematococcus pluvialis. Mar Drugs. 2017;15:304.

23. Fernández E, Galván A, Quesada A. Nitrogen assimilation and its regulation. In: Rochaix JD, Goldschmidt-Clermont M, editors. Molecular Biology of Chlamydomonas: Chloroplast and Mitochondria. Dordrecht: Kluwer Academic Publishers: 1998. p. 637-59.

24. de Montaigu A, Sanz-Luque E, Galvan A, Fernandez E. A soluble guanylate cyclase mediates negative signaling by ammonium on expression of nitrate reductase in Chlamydomonas. Plant Cell. 2010;22:1532-48.

25. Muños-Blanco J, Hidalgo-Martinez J, Cárdenas J. Extracellular deamination of L-amino acids by Chlamydomonas reinhardtii cells. Planta. 1990;182:194-8.

26. Calatrava V, Chamizo-Ampudia A, Sanz-Luque E, Ocaca-Calahorro F, Llamas A, Fernandez E, Galvan A. How Chlamydomonas handles nitrate and the nitric oxide cycle. J Exp Bot. 2016. https://doi.org/10.1093/jxb/erw507.

27. Chamizo-Ampudia A, Sanz-Luque E, Llamas A, Ocaca-Calahorro F, Ma cal V, Carreras A, Barroso JB, Galvan A, Fernandez E. A dual system formed by the ARC and NR molybdoenzymes mediates nitrite-dependent NO production in Chlamydomonas. Plant Cell Environ. 2016;39:2097-107.

28. Sanz-Luque E, Ocaca-Calahorro F, de Montaigu A, Chamizo-Ampudia A, Llamas A, Galvan A, Fernandez E. THB1, a truncated hemoglobin, modulates nitric oxide levels and nitrate reductase activity. Plant J. 2015;81:467-79.

29. Minaeva E, Zalutskaya Z, Filina V, Ermilova E. Truncated hemoglobin 1 is a new player in Chlamydomonas reinhardtii acclimation to sulfur deprivation. PLoS One. 2017. https://doi.org/10.1371/journal.pone.0186851.

30. Sosa FM, Ortega T, Barea JL. Mutants from Chlamydomonas reinhardii affected in their nitrate assimilation capability. Plant Sci Lett. 1978;11:51-8.
31. Baker CJ, Mock MM. An improved method for monitoring cell death in cell suspension and leaf disc assays using Evans blue. Plant Cell Tissue Organ Cult. 1994:39:7-12.

32. Harris EH. The Chlamydomonas sourcebook: a comprehensive guide to biology and laboratory use. San Diego: Academic Press; 1989.

33. Zalutskaya Z, Ostroukhova M, Ermilova E. The Chlamydomonas alternative oxidase 1 is regulated by cadmium stress: new insights into control of expression. Environ Exp Bot. 2016;130:133-40.

34. Livak KJ, Schmittgen TD. Analysis of relative gene expression data using real-time quantitative PCR and the $2^{-\Delta \Delta C T}$ method. Methods. 2001;25:402-8.

35. Zalutskaya Z, Lapina T, Ermilova E. The Chlamydomonas reinhardtii alternative oxidase 1 is regulated by heat stress. Plant Physiol Biochem. 2015;97:229-34

36. Dong G, Zhang W, Yang R, Yang Y, Yu Y, Zhang X. Determination of nitrate nitrogen in soil based on K ratio spectrophotometry. Int Conf Instr Meas. 2014. https://doi.org/10.1109/IMCCC.2014.117.

37. Fernandez E, Galvan A. Inorganic nitrogen assimilation in Chlamydomonas. J Exp Bot. 2007;58:2279-87.

38. Fernandez E, Galvan A. Nitrate assimilation in Chlamydomonas. Eukaryot Cell. 2008;7:555-9.

39. de Montaigu A, Sanz-Luque E, Macias MI, Galvan A, Fernandez E. Transcriptional regulation of CDP1 and CYG56 is required for proper $\mathrm{NH}_{4}^{+}$ sensing in Chlamydomonas. J Exp Bot. 2011;62:1425-37.

40. Floryszak-Wieczorek J, Milczarek G, Arasimowicz M, Ciszewski A. Do nitric oxide donors mimic endogenous NO-related response in plants? Planta. 2006:224:1363-72

41. Zhao Y, Brandish PE, DiValentin M, Schelvis JPM, Babcock GT, Marletta MA. Inhibition of soluble guanylate cyclase by ODQ. Biochemist. 2000;39:1084854.

42. Quesada A, Galvan A, Schnell RA, Lefebvre PA, Fernandes E. Five nitrate assimilation-related loci are clustered in Chlamydomonas reinhardtii. Mol Gen Genet. 1993;240:387-94.

43. Loppes R, Ohresser M, Radoux M, Matagne RF. Transcriptional regulation of the Nit1 gene encoding nitrate reductase in Chlamydomonas reinhardtii: effect of various enviromental factors on the expression of a reporter gene under the control of the Nit1 promoter. Plant Mol Biol. 1999;41:701-11.

44. Ferrario-Mery S, Meyer C, Hodges M. Chloroplast nitrite uptake is enhanced in Arabidopsis PII mutants. FEBS Lett. 2008;582:1061-6.

45. Perazzolli M, Dominici P, Romero-Puertas MC, Zago ED, Zeier J, Sonoda M, Lamb C, Delledonne M. Arabidopsis non-symbiotic haemoglobin AHb1 modulates nitric oxide bioactivity. Plant Cell. 2004;16:1-10.

46. Johnson EA, Rice SL, Preimesberger MR, Nye DB, Gilevicius L, Wenke BB, Brown JM, Witman JB, Lecomte JTJ. Characterization of THB1, a Chlamydomonas reinhardtii truncated hemoglobin: linkage to nitrogen metabolism and identification of lysine as the distal heme ligand. Biochemistry. 2014:53:4573-89.

47. Nioche P, Berka V, Vipond J, Minton N, Tsai AL, Raman CS. Femtomolar sensitivity of a NO sensor from Clostridium botulinum. Science. 2004;306: 1550-3.

48. Düner M, Lambertz J, Mügge C, Hemschemeier A. The soluble guanylate cyclase CYG12 is required for the acclimation to hypoxia and trophic regimes in Chlamydomonas reinhardtii. Plant J. 2017. https://doi.org/10.1111/ tpj.13779.

49. Gonzalez-Ballester D, Sanz-Luque E, Galvan A, Fernandez E, de Montaigu A. Arginine is a component of the ammonium-CYG56 signalling cascade that represses genes of the nitrogen assimilation pathway in Chlamydomonas reinhardtii. PLoS One. 2018. https://doi.org/10.1371/journal.pone.0196167.

50. Derbyshire ER, Marletta MA. Structure and regulation of soluble guanylate cyclase. Annu Rev Biochem. 2012:81:533-59. 